The Journal of Nepalese Business Studies Vol. XIV No. 1 December 2021 ISSN 2676-1238 (Online)

(A Peer-Reviewed, Open Access Journal)

\title{
Individual, Family Factors and Career Development of Female School Teachers
}

\author{
Sarita Maharjan
}

DOI: https://doi.org/10.3126/jnbs.v14i1.41497

Received on 2 April 2021

Accepted on 21 October 2021

\section{ABSTRACT}

In Nepalese society, female people feel that they are facing many obstacles in their career development such as individual, family, organization barriers, etc. In this regard, this study is conducted to analyze barriers in female career development. So, the study's main objective is to analyze the impact of individual and family barriers on female school teachers' career development. A causal effect research design has been employed in this study to analyze the impact of the barriers on female career development. The study used a judgmental sampling technique to gather the real picture of data from female school teachers in Kathmandu valley. Multiple regression analysis techniques has been adopted to analyze the data. From the result of data analysis, it is concluded that the family issue has hampered the career development of female school teachers. This means that Nepalese female teachers have to do their office duty along with giving time for their family members, housework and child-caring, etc. This could be beneficial to school administrators, trainers, and human resource professionals who want to help female teachers for the advancement of their careers.

Keywords: Female teachers, individual factor, family factor, career development

\section{INTRODUCTION}

Several invisible barriers have to be faced by females in their career development in Nepal. Even though Nepal's law has provided the provisions of gender equality, the society is still following a male-dominated system. Thus, Nepalese female people have to balance office work along with family responsibility. The Nepalese female teachers have to do their official duty in addition to giving time for their family members, housework and child-caring, etc. They can do nothing without the permission of the family. So, they also lose their self-confidence, ability, self-perception, risk-taking capacity, etc. Not only that only a few females have been able to reach the higher position of the job and also Nepalese society deprives the female people in their career development.

In Nepal's current situation, female school teachers are progressing better. According to the Government of Nepal (2020), the number of female school teachers at the basic level is increasing continuously from 38.8 percent (in 2015) to 43.7 percent (in 2019). Likewise, female

\footnotetext{
- Mrs. Maharjan is a faculty member at Shankar Dev Campus, Tribhuvan University.

Email: saritamaharjan78@gmail.com
} 
school teachers are increasing from 14.1 percent (in 2015) to 19.8 percent (in 2019) at the secondary level. In this way, Nepalese female school teachers are growing annually over the period.

In Nepal, the female population is more than the male population (Central Bureau of Statistics, 2009). According to the Central Bureau of Statistics (2009), female people occupied 52.77 percent out of the total population. However, there are still several obstacles that prevent females from obtaining top-level positions in the service sector. Despite the development of a favorable attitude toward females, little effort has been made to advance the careers of female employees.

A study conducted in Greece study among women in management by Kottis (1996), states that despite the continued growth in the number of females in business schools, only a small percentage of women are found in managerial positions, and their entry into the social control ranks is far under their male counterparts. The impact on employees varies according to culture, with Nepali culture having a different impact on women than Western societies (Luthans, 2010).

Women have been increasing their participation in the labor force since the 1970s. Powell and Graves, (2003) reveal that the share of ladies in managerial positions has up in the majority of countries. Women are asking for more equality in the workplace. Gender disparities are one of the primary reasons that must be considered to attain equality in the workplace. Moreover, factors such as education, government regulations, media pictures, and opinion leaders can reshape and affect gender disparities and levels.

Mathis and Jackson's (2008) results depict that career development permits organizations to draw in and retain economical and effective people that can contribute to the action of the organization's goals and objectives. As a result, workers will attain their individual career goals and objectives. Mavin (2000) demonstrated that female managers and professionals were not progressing to top management positions at the same pace as their male contemporaries due to some obstacles that females face in developing their careers. Female managers were still scarce at the highest levels of business. Alvesson and Billing (2009) has prioritized female employment for female career development. This is expected as a result of a growing range of females' area unit within the personnel, however solely an awfully little proportion holds the best positions in business and public administration.

Bombuwela and DeAlwis(2013) explain that individual factors had a negative significant impact on the career development of females. However, there was no significant effect of the family factor. Individual and family factors had a considerable detrimental impact on career development(Victor \& Shamila, 2018). Uduwella and Jayatilaka (2019)unconcealed that individual factors had a major positive impact on females' career development. Thus, selfefficacy beliefs and private growth initiatives favor female career development. Family factors specifically, kid care and relative care, elder care, and housekeeping had no significant impact on female career development.

The main objectives of this study are to investigate the relationship of female school teachers' career development with individual and family factors and to examine the impact of individual factors and family factors on female school teachers' career development.

\section{LITERATURE REVIEW}

Bombuwela and De-Alwis (2013) examined the impact of the glass ceiling on women's career development within the private sector in Sri Lanka. The goal of the study was to investigate how the glass ceiling affected the career development of female executive-level staff 
within the non-public sector. It was applied with the assistance of a self-administered form and a hundred and fifty feminine executives' area unit designated as a sample. To show and analyze the information, descriptive and inferential statistics were used. Individual, organizational, and cultural factors all had a negative significant impact on women's career development, however, the impact of the family issue wasn't significant.

Subramaniam et al. (2016) revealed the influence of the glass ceiling on women's career advancement in Malaysia. Purposive and quota sampling approaches were used to distribute a self-administered questionnaire to 300 working women. According to a descriptive and crosstabulation study, it was found that the key challenges of the "glass ceiling" that hampers women's professional growth in Malaysia are family commitment, corporate culture, and career advancement chances.

Jauhar and Lau (2018)investigated the impact of the 'glass ceiling' on women's career development to prime management. A quantitative approach was employed in this study, with a hundred and forty female respondents finishing self-administered questionnaires. Within the information analysis, organizational culture, organizational networking, and organizational practices were found to own a significant effect on women's career growth, whereas family and personality factors had no significant effect.

Victor and Shamila (2018)studied the consequences of the glass ceiling on the career development of executive-level female staff members. The goal of the study was to identify the effect of the glass ceiling on women's career advancement within the banking sector in the Kandy district. A structured questionnaire was used to gather information from one hundred forty-four executive-level feminine respondents, out of 157 executive-level female staff members. The study's key finding was that there's a small negative significant relationship between the glass ceiling and women's career progression which individual, familial, and cultural factors have a significant impact on women's career development, but the organizational factor is not significant.

Azeez and Priyadarshini (2018) analyzed the glass ceiling factors affecting women's career advancement within the IT trade in India. The study aimed to identify the elements that contribute to the glass ceiling and impede women's job advancement. It additionally tries to determine that of the listed factors contributes the foremost to women's skilled growth opportunities. The sample consists of fifty-seven feminine workers from varied IT corporations who add middle and senior management positions. In step with the study of the information gathered, social constraints impede women's advancement in their jobs the foremost, however, individual and familial factors even have a considerable impact on women's career advancement.

Alsharif (2018)studied the challenges associated with the career development of women at Saudi Arabian State Universities. The goal of this article was to identify the obstacles that women face in their professional growth at Saudi Arabian state universities. The descriptive research design was employed to depict the study's actual scenario. Universities have provided a sample size of forty people. The survey results revealed seven major obstacles to women's career advancement: culture, family, individual, organization, region, economy, law, and constitution.

Lama (2019) analyzed the results of the glass ceiling of female career development in banks of Pokhara city, Nepal. The respondents for this survey were female employees, with a total sample size of 99. The research reveals that social barriers, personal barriers, and organizational barriers all have a major impact on women's employment development.

According to Kuruppuarachchi and Surangu (2020), the number of women joining the job is increasing, but top leadership roles are still scarce. The major purpose of this study is to investigate the concept of a glass ceiling and female career advancement in Sri Lanka's readymade garment industry. According to the findings, individual, organizational, and social hurdles all played a part in women's access to top leadership positions. 
Lakmali et al. (2020) examined the impact of the glass ceiling on women's career success. The study includes 214 female lecturers from two universities as a sample size. The data show that familial and organizational factors have a highly significant impact on women's professional development, while individual and educational factors have a low impact.

Dauti and Dauti (2020) investigated the impacts of the glass ceiling on women's career development in the private sector of the hospitality industry in Kosovo. The study's major goal was to assess and investigate the hurdles to women's advancement in the workplace. The data was obtained from one hundred and fifty women who work in the hospitality industry, with 132 responding to the poll. Internal business structural hurdles, governmental barriers, and personal barriers were determined to have a negative significant influence on women's career progression, however societal and situational barriers were found to have a positive significant impact.

In the prior studies, some research gaps were found. Previous res earchers looked into several businesses such as banks and manufacturing, but very few studies on the education sector were found. Regardless, this research has expanded the study relating to the service sector of school teachers (up to secondary level). The majority of prior studies failed to reveal what elements influence female school teachers' career advancement. Using multiple regression analysis, however, this study attempts to investigate the influencing elements on female career development, such as individual and family factors. However, this study attempts to investigate the impact of influencing factors such as individual and family influences on female career advancement. So, this study tries to fill the aforesaid research gap to some extent. To analyze the data for this study, it is hypothesized that there is a significant impact of individual and family factors on female career development.

\section{RESEARCH METHODOLOGY}

The causal-effect research design has been employed to fulfill the objectives of the study. The research design has been used in this study to analyze the impact of individual and family factors on female career development. A judgmental sampling technique has been used to collect the data. The population for the study consists of school female teachers in Kathmandu valley. Out of 180 questionnaires distributed to school female teachers in Kathmandu valley, only71 percent of respondents were selected and usable. Quantitative data were collected through questionnaires from primary sources using close-ended questions. Views of the female teachers were collected through Five-Point Likert Scale, where 1 for "strongly disagree", 2 for "disagree", 3 for "fairly agree",4 for "agree" and 5 for "strongly agree". This scale attempts to identify whether a particular variable was a barrier to female career development.

The reliability of the responses of the respondents is tested by using Cronbach alpha. The values of Cronbach alpha of individual factors, family factors, and female career development are found as 0.787, 0.749, and 0.824 respectively. According to George and Mallery (2009), the Cronbach alpha value should be more than 0.7 in order to accept the respondents' responses as reliable.

Since the value of Cronbach alpha is greater than 0.7 , all the questionnaires of the specific variables employed for the data analysis are reliable. The response rate of the individual factor is 99.30 percent. The response rate of family factors is 98.71 percent whereas the response rate of female career development is 99.18 percent. The missing percent of individual factors, family factors, and female career development are 0.70,1.29, and 0.82 respectively. These response rates of variables appear sufficient for the analysis of data. 
The correlation analysis technique has been adopted to examine the relationship of female career development with individual factors and family factors. The multiple regression analysis techniques have been implemented to examine the impacts of independent variables on the dependent variable. For this, female career development is regressed on individual factors and family factors. In the regression model, multicollinearity problems should not arise. Hence, to identify the problem of multicollinearity amongst independent variables, tolerance and VIF have been evaluated.

As barriers to female professional advancement, this study only looked at two independent variables: individual and familial issues. Only the teachers at the school level in Kathmandu valley are taken as a sample. As a result, the study's conclusions cannot be applied to other firms' female employees. The analytical tools used to investigate the link and influence of the variables are limited to correlation and regression models.

\section{Figure 1}

\section{Conceptual Framework}

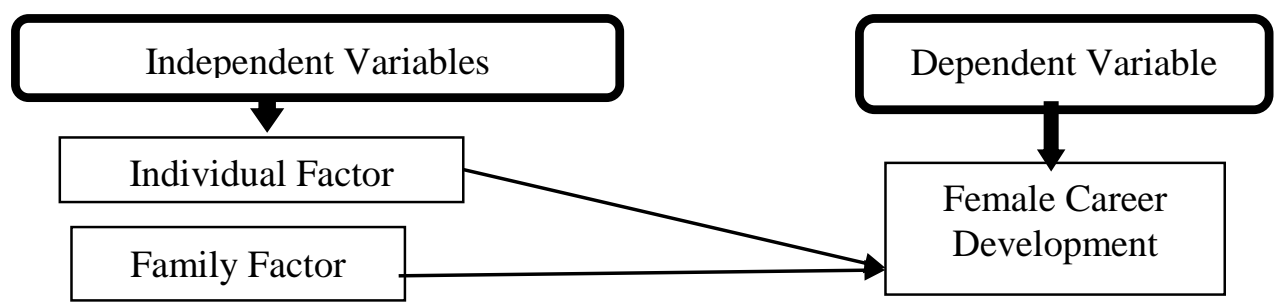

The study has taken individual factor and family factor as the independent variables while female career development as the dependent variable.

Regression Model: FCD $=\alpha+\beta_{1} I F+\beta_{2} F F+\mathrm{U} \ldots(1)$

Where,

$\mathrm{FCD}=$ Female Career development

$\mathrm{IF}=$ Individual Factor; FF = Family Factor

$\alpha=$ constant $\beta_{1}$ and $\beta_{2}=$ coefficients of variables; $U=$ Error term

\subsection{Variable Definitions}

Female Career Development: Career development refers to getting promoted or being assigned more responsibilities by an employer. Women are thought to have fewer prospects for growth in their careers than men. According to career development, good psychological or jobrelated consequences, as well as personal and professional accomplishments, are derived from one's work experience.

Individual factor: It consists of those personal factors such as education, self-perception, motivation, capacity to work, hard work, effective communication, problem-solving skills, and willingness to accomplish the assigned job are all elements that might influence career development. 
Family factor: It refers to activities about the upbringing of children, as well as the providing of goods and services to the family. It is the encouragement given by family members to help an individual achieve in his or her work.

\subsection{Respondents Profile}

Table 1 illustrates the age group, academic qualification, Family Status, Marital Status, Children, Organization Type, Job Category, Experience, and Monthly Income of the 142 respondents. The table also shows the percentage distributions of respondents across all groups. The age group of 30 to 50 years has the maximum percentage of respondents $(59.9 \%)$, while the age group of 50 years and above has the lowermost percentage of respondents $(4.9 \%)$. Similarly, the highest percentage of respondents $(49.3 \%)$ indicated a bachelor's degree in academic qualification. Likewise, the nuclear family has the highest percentage of respondents i.e., 53.5 percent. From the viewpoint of marital status, married respondents are designated as the highest (74.6\%). In addition, the respondents having children are selected as 73.9 percent. Further, most of the respondents are nominated from private organizations (75.4\%). Likewise, full-time teachers are collected mostly (97.2\%). In the experience, the uppermost percentage of respondents are below 10 years i.e., 66.2 percent. The highest monthly earning respondents are 67.6 percent, which is below Rs 20,000 .

Table 1

Distribution of Respondents

\begin{tabular}{|c|c|c|c|}
\hline Variable & Category & Number of respondents & Percent \\
\hline \multirow{3}{*}{ Age group } & Below 30 & 50 & 35.2 \\
\hline & $30-50$ & 85 & 59.9 \\
\hline & $50 \&$ above & 7 & 4.9 \\
\hline \multirow{3}{*}{$\begin{array}{l}\text { Academic } \\
\text { qualification }\end{array}$} & Under bachelor & 42 & 29.6 \\
\hline & Bachelor & 70 & 49.3 \\
\hline & Master \& above & 30 & 21.1 \\
\hline \multirow{2}{*}{ Family status } & Nuclear family & 76 & 53.5 \\
\hline & Joint family & 66 & 46.5 \\
\hline \multirow{3}{*}{ Marital status } & Unmarried & 32 & 22.5 \\
\hline & Married & 106 & 74.6 \\
\hline & Divorced & 4 & 2.8 \\
\hline \multirow{2}{*}{ Children } & No child & 37 & 26.1 \\
\hline & Having children & 105 & 73.9 \\
\hline \multirow{2}{*}{$\begin{array}{l}\text { Organization } \\
\text { Type }\end{array}$} & Public (govt) & 35 & 24.6 \\
\hline & Private & 107 & 75.4 \\
\hline \multirow{2}{*}{ Job category } & Part-time & 4 & 2.8 \\
\hline & Full time & 138 & 97.2 \\
\hline \multirow{4}{*}{ Experience } & Below 10 years & 94 & 66.2 \\
\hline & 10 to 20 years & 31 & 21.8 \\
\hline & 20 to 30 years & 14 & 9.9 \\
\hline & 30 years \& above & 3 & 2.1 \\
\hline \multirow{3}{*}{$\begin{array}{l}\text { Monthly } \\
\text { income }\end{array}$} & Below Rs 20,000 & 96 & 67.6 \\
\hline & Rs $20,000-50,000$ & 44 & 31.0 \\
\hline & Rs $50,000 \&$ above & 2 & 1.4 \\
\hline
\end{tabular}

Source: Survey, 2019 


\section{RESULTS AND DISCUSSION}

In this section, data are analyzed based on the responses of respondents. Respondents' response rates, reliability tests, correlation analysis, multicollinearity test, and multiple regression analysis have been adopted to examine the data.

\subsection{Relationship of Variables}

Table 2 shows the relationship of female career development with individual factors and family factors. The correlation coefficient of female career development with individual factors is-0.125and the corresponding $\mathrm{p}$-value of the $\mathrm{t}$-statistic is 0.140 which is greater than 0.1 (i.e., $p>0.1$. Since the p-value is greater than 0.1, the correlation coefficient is not significant even at the 10 percent level. Similarly, the correlation coefficient of female career development with family factors0.479 and the corresponding $p$-value of the t-statistic is 0.000 (i.e., $p<0.01$ ). Since the pvalue is less than 0.01 , the coefficient of correlation between female career development and family factor is significant at one percent level and the negative sign of the coefficient shows the negative relationship. Thus, the correlation analysis shows that the relationship of female career development with family factors is negatively significant but it is not significant with individual factors.

As far as multicollinearity is concerned, Table 2 shows that the tolerance and VIF are 0.870 (i.e., tolerance $>0.1$ ) and 1.149 (i.e., VIF $<10$ ) respectively. Meanwhile tolerance is more than 0.1 andVIF is less than 10 , there is no multicollinearity problem in this situation according to Hair et al. (2009).

Table 2

Correlation and Multicollinearity Test

\begin{tabular}{lcccc}
\hline \multirow{2}{*}{ Variable } & $\begin{array}{c}\text { Correlation } \\
\text { Coefficient }\end{array}$ & \multirow{2}{*}{ P-value } & \multicolumn{2}{c}{$\begin{array}{c}\text { Multi-collinearity } \\
\text { statistics }\end{array}$} \\
\cline { 4 - 5 } & $(\mathrm{r})$ & & Tolerance & VIF \\
\hline Individual factor & -0.125 & 0.140 & 0.870 & 1.149 \\
Family factor & $-0.479^{*}$ & 0.000 & 0.870 & 1.149 \\
\hline
\end{tabular}

Dependent variable: Female career development

* Correlation is significant at the 0.01 level (two-tailed).

Source: Author's calculation from Survey, 2019

\subsection{Impact of Individual and Family Factors on Female Career Development}

The Regression analysis technique is employed to test the impact of individual factors and family factors on female career development. Table 3 shows the regression model of data analysis. In this model, FCD refers to Female Career Development, FF refers to Family Factor and IF refers to Individual Factor.

From Table 3, the corresponding p-value of F-statistic is $0.000(p<0.01)$. Since the pvalue is less than 0.01 , the F-statistic is significant at the 1 percent level. Therefore, the model is fit. The $\mathrm{R}^{2}$ valueis 0.439 i.e., 43.9 percent, this means that 43.9 percent variation in female career development is explained by variation in individual factors and family factors.

In Table 3, the regression model shows that the corresponding p-values of individual factors and is 0.490 ( $p>0.10)$. Here, the $p$-value of the individual factor is more than 0.10 . Thus, the concerned t-statistic of individual factors is not significant even at 10 percent level. 
Hence, hypothesis 1 cannot be accepted. This indicates that there is no significant impact of individual factors on female career development. Likewise, the corresponding $\mathrm{p}$-value of the family factor is 0.000 , which is less than 0.01 (i.e., $\mathrm{p}<0.01$ ). Since the corresponding $\mathrm{p}$-value is less than 0.01 , the t-statistic is significant at the 1 percent level. So, thehypothesis 2 is accepted. The sign of the coefficient is negative. Thus, the result shows that there is a negative significant impact of the family factor on female career development. The value of the coefficient of the family factor is -0.437 . This indicates that a 1 percent change in family factor leads to a 0.437 percent change in female career development negatively.

Table 3

Regression Model

Hypothesis 1: There is a significant impact of individual factor on female career development.

Hypothesis2: There is a significant impact of family factor on female career development.

\begin{tabular}{llllll}
\hline FCD & 4.224 & $+0.055 I F$ & $-0.437 F F$ & $+\mathrm{U}$ & $\ldots(1)$ \\
$\mathrm{Se}$ & $(0.257)$ & $(0.080)$ & $(0.070)$ & & \\
$\mathrm{p}$-value & $\{0.000\}$ & $\{0.490\}$ & $\{0.000\}$ & & \\
\hline F: $21.012(\mathrm{p}=0.000)$ df: $(2,139)$ & \multicolumn{3}{c}{$\mathrm{R}^{2}: 0.439$ or $43.9 \%$} \\
\hline
\end{tabular}

Source: Author's calculation from the survey, 2019

The correlation analysis shows that the correlation coefficient of female career development with individual factors is not significant. This indicates that there is no significant relationship between individual factors with female career development. But, the correlation coefficient of female career development with family factors is negative and significant. In this way, female school teacher expresses their views that there is a significant negative relationship of female career development with family factor but not significant with individual factor.

Further, the regression model reveals that there is a negative significant impact of the family factor on female career development but the individual factor is not significant. Thus, hypothesis 2 is accepted but hypothesis 1 cannot be accepted. Moreover, the coefficient of family factor shows that change in one percent of family factor leads to a 0.43 percent change in female career development negatively.

According to the results of the hypothesis testing, the individual factor has no significant impact on female career advancement, but the family factor has a negative significant impact. This differs from the findings of Uduwella and Jayatilaka (2019), who found that individual factors had a significantly positive impact on females' career development. Family factors had no significant effect on female career development. Furthermore, Victor and Shamila (2018) counter these results, claiming that individual and family factors had a significant impact on the career development of executive-level female employees in the banking sector in the Kandy region. Additionally, individual factors had a negative significant impact on career development according to Bombuwela and De-Alwis (2013). However, no significant effect of a family factor on career development was revealed, and this outcome is not alike.

\section{CONCLUSION AND IMPLICATIONS}

The female teachers from Nepalese schools are taken as a sample in this study. As a result of the study, it can be concluded that family issues are substantial barriers to the career development of female school teachers in Nepal, but that individual characteristics have no bearing on female career development. This research suggests that family difficulties play an 
essential role in the professional growth of female school teachers. Women must be helped to succeed in their careers by organizations, their families, and society as a whole.

Female employees have to encounter barriers to promotion as long as the underlying conservative mentality prevails. Female educators should be encouraged to modify their views, traditions, and preconceptions, but they should also be supported in their social relationships and given opportunities to grow in their careers. Similarly, policies, structures, cultures, and perceptions all have a part in women's success in the workplace. Aside from that, job recruiting, job assignment, and mentoring, as well as retention and training, promotion, and reward systems, all aid women in their career advancement.

This study has significance for female school teachers' professional growth. To aid female career development, this research could be valuable to school administrators, instructors, mentors, trainers, and human resource managers. Women should place a higher priority on their careers than on their employment. They should learn how to analyze critically and methodically, as well as how to use role models in the workplace. Females should receive specialized instruction. To expedite upward managerial mobility and career life planning skills, this should incorporate confidence-building and assertiveness training, as well as management capabilities.

Everyone should be given an equal chance during training. Concerned authorities should not discriminate against female employees when assigning responsibilities. Organizations must have objective-based HR policies that govern recruiting, training and development, performance evaluations, and promotions. Developing training programs targeted at changing attitudes and establishing an environment conducive to women's empowerment are two further options.

\section{ACKNOWLEDGMENTS}

I would like to express my gratitude to the University Grants Commission (UGC) of Nepal for the financial assistance in finishing my research for this article. This encouragement has pushed me to finish my research work in such fine shape.

\section{REFERENCES}

Alsharif, S. A. (2018). The challenges associated with women career development at the State Universities in Saudi Arabia: A ground theory approach. International Journal of Gender and Women's Studies, 6(2), 18-30. https://doi.org/10.15640/ijgws.v6n2p3

Alvesson, M., \& Billing, Y. D. (2009). Understanding gender and organizations. Sage.

Azeez, P. V. N., \& Priyadarshini, R. G. (2018). Glass ceiling factors affecting women career advancement in IT industry in India. Iopscience.Iop.Org, 1-8. https://doi.org/10.1088/1757899X/390/1/012021

Bombuwela, P. M., \& De-Alwis, A. C. (2013). Effects of glass ceiling on women career development in private sector organizations - Case of Sri Lanka. Journal of Competitiveness, 5(2), 3-19. https://doi.org/10.7441/JOC.2013.02.01

Central Bureau of Statistics. (2009). Report on the Nepal labour force survey 2008 - Statistical report. https://www.ilo.org/wcmsp5/groups/public/@asia/@ro-bangkok/@ilo-kathmandu/ documents/publication/wcms_118294.pdf

Dauti, M. B., \& Dauti, R. (2020). The glass ceiling: Existence barriers affecting women's career development. Scholar.Archive.Org, 8(4), 111-121. 
George, D., \& Mallery, P. (2009). SPSS for Windows step by step (18th ed.). Dorling Kindersley. Government of Nepal. (2020). Economic Survey 2019/20. In Ministry of Finance.

Hair, J. F., Black, W. C., Babin, B. J., \& Anderson, R. E. (2009). Multivariate data analysis (7 $7^{\text {th }}$ ed.). Prentice Hall.

Jauhar, J., \& Lau, V. (2018). The Glass Ceiling and women's career advancement to top management: The moderating effect of social support. Global Business \& Management Research: An International Journal, 10(1), 163-178.

Kottis, A. P. (1996). Women in management and the glass ceiling in Greece: An empirical investigation. Women in Management Review, 11(2), 30-38.

Kuruppuarachchi, K. A. P. S. T., \& Surangu, H. A. K. N. S. (2020). The glass ceiling and women career advancement: A study based on ready - Made garment industry in Sri Lanka. Kelaniya Journal of Management, 8(2), 18. https://doi.org/10.4038/KJM.V8I2.7581/

Lakmali, T. A. H., Madawala, R. M. D. A. K., Arachchi, D. C. W., \& Weerarathna, R. S. (2020). Effects of glass ceiling on women career blooming in Sri Lankan Academic Sector. South Asian Journal of Social Studies and Economics, 5(4), 1-12. https://doi.org/10.9734/ sajsse/2019/v5i430152

Lama, B. (2019). Effect of glass ceiling on women's career development in banks operating in Pokhara Metropolitan City. Journal of Nepalese Business Studies, 12(1), 100-110. https://doi.org/10.3126/JNBS.V12I1.28186

Luthans. (2010). Organizational behavior. In McGraw-Hills (Vol. 1, Issue 1).

Mathis, R. L., \& Jackson, J. H. (2008). Human resource mangement (12 $2^{\text {th }}$ ed.). Thomson SouthWestern.

Mavin, S. (2000). Approaches to careers in management: Why UK organisations should consider gender. Career Development International, 5(1), 13-20. https://doi.org/10.1108/ 13620430010309323/FULL/HTML

Powell, G. N., \& Graves, L. (2003). Women and men in management. Sage.

Subramaniam, G., Khadri, N. A. M., Maniam, B., \& Ali, E. (2016). The glass ceiling phenomenon-Does it really affect women's career advancement in Malaysia? Researchgate.Net, 20(1), 81-89.

Uduwella, U., \& Jayatilaka, M. (2019). Impact of glass ceiling on women career development in non-state banking sector in Colombo. Tropical Agricultural Research, 30(3).

Victor, L. D., \& Shamila, F. A. (2018). The impact of glass ceiling on career development of executive level female employees in financial sector in Kandy district. Asian Journal of Advanced Research and Reports, 2(4), 1-11. https://doi.org/10.9734/ajarr/2018/v2i429773 